\title{
Revising the risk of Alzheimer disease in women
}
Among individuals who carry the apolipoprotein $\mathrm{E} \varepsilon 4\left(\mathrm{APOE}^{*} \varepsilon 4\right)$ allele, women are more suscepti- ble to Alzheimer disease (AD) than men only between the ages of 65 and 75 years, according to a new study published in JAMA
Neurology. The results con- tradict a 20 -year-old belief that female carriers of $A P O E^{*} \varepsilon 4$ have a higher risk of $\mathrm{AD}$ than male carriers across all ages, and provide clues towards disease mechanisms and possible interventions.
Apolipoprotein E is a glycoprotein associated with lipid and neuronal homeostasis in the brain. One of its isoforms, encoded by the $A P O E^{*} \varepsilon 4$ allele, is the main genetic risk factor for late-onset $\mathrm{AD}$ in both sexes.
"We were surprised that so much work over the last 20 years has been dependent on one 1997 study, which reported that white females with one $A P O E^{\star} \varepsilon 4$ allele have a higher risk over men at all ages," comments Arthur Toga, who led the new study. "Using a new big data platform, the Global Alzheimer's Association Interactive Network, we saw that we had nine times the data of the 1997 study and decided to take a second look."
Toga and colleagues analysed data from 27 independent studies on 57,979 individuals from North America and Europe between the ages of 55 and 85 years to determine how $A P O E^{\star} \varepsilon 4$ and sex affected the risk of developing $\mathrm{AD}$ and mild cognitive impairment (MCI). "We were able to aggregate vast amounts of data from independent studies, affording increased statistical power

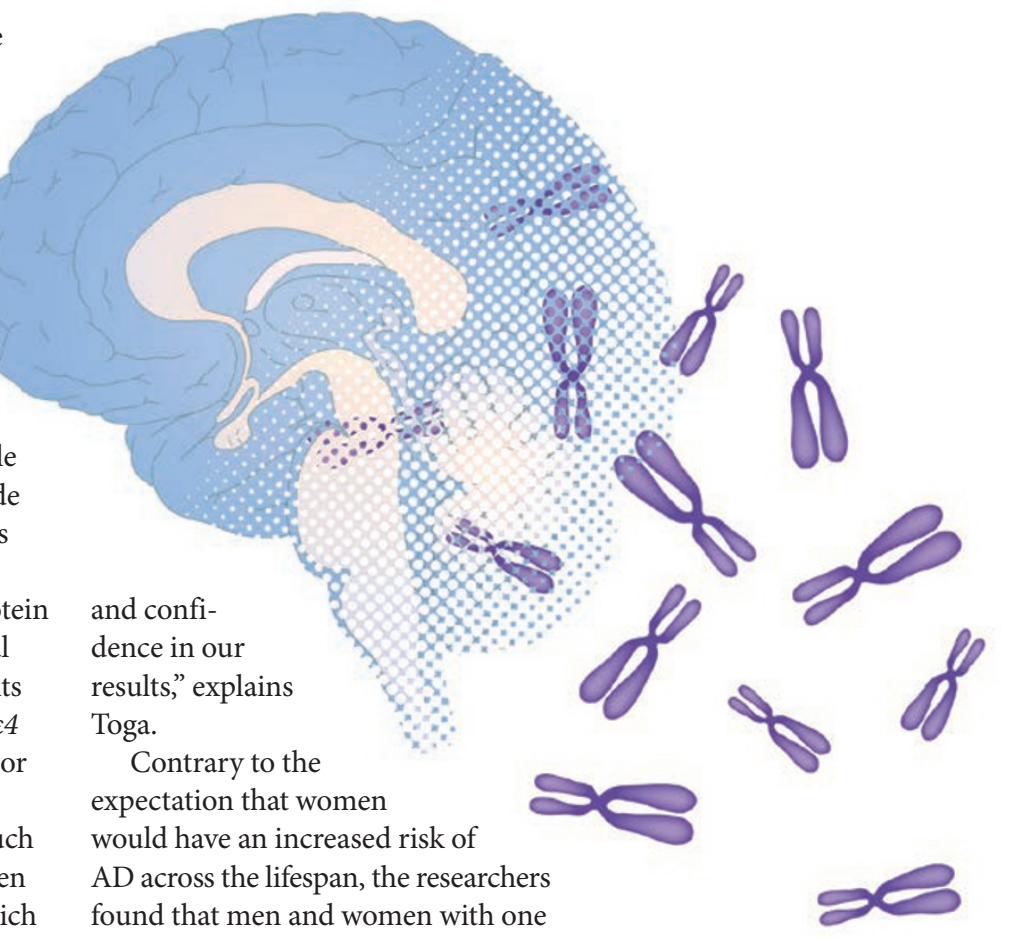
copy of $A P O E^{\star} \varepsilon 4$ had the same risk of MCI and AD between the ages of 55 and 85 years. However, compared with men, women had a higher risk of $\mathrm{AD}$ between the ages of 65 and 75 years, as well as an increased risk of developing MCI between the ages of 55 and 70 years.
As the pathophysiology of $\mathrm{AD}$ takes place over decades, the team suggests that the increased risk of $\mathrm{AD}$ in women between the ages of 65 and 75 years is associated with physio- logical events that occur 15-20 years earlier, possibly coinciding with the menopause. "We find that women have a slightly earlier incidence of $\mathrm{AD}$ and MCI, which may in fact be related to hormonal changes," explains Toga. "The mean start of menopause is somewhere around
51 years of age; at that point, there is a relative loss of oestrogen, which might interact with the presence of one or more copies of the $A P O E^{*} \varepsilon 4$ allele."
Crucially, the results could lead to the development of sex-specific bio- markers or interventions in $\mathrm{AD}$. As Toga concludes, "researchers could study women 10,15 or even 20 years before their most vulnerable period, to see if there are any detectable signals to suggest an increased risk of $\mathrm{AD}$ in 15 years."
Mitesh Patel
ORIGINAL ARTICLE Neu. S. C. et al. Apolipoprotein E genotype and sex risk factors for Alzheimer disease: a meta-analysis. JAMA Neurol. http://dx.doi.org/10.1001/jamaneurol.2017.2188 (2017)

We find that women have a slightly earlier incidence of $\mathrm{AD}$ and $\mathrm{MCl}$ 